\title{
Mixed Methods Evaluation of a Movement and Mindfulness Empowerment Workshop for Adults with Serious Mental Illness
}

\author{
Michael L. Clarkson-Hendrix \\ Paula J. Peters
}

\begin{abstract}
For seriously mentally ill adults, empowerment is critical to maximizing participation in major life activities. Although studies have identified interventions that have positively impacted empowerment, these interventions may not be applicable or amenable to all adults with serious mental illness. More interventions with other approaches are needed. Therefore, this study evaluated the initial implementation of a movement-and mindfulness-based workshop intervention. Quantitative data were used to examine differences in empowerment before and after the workshop, and qualitative data were used to explore participants ' perceptions of the reasons for empowerment differences. Ten participants completed the intervention, and nine of the ten participants also completed follow-up interviews. Quantitative data were collected via pre- and postintervention surveys. Qualitative data were collected through follow-up interviews with the participants. Surveys revealed perceptions of optimism and control over the future increased between pre- and post-intervention. Interviews uncovered that increases in optimism and control over the future may have been related to workshop accomplishments and reduced helplessness outside of workshop sessions. Future research would benefit from the creation of a training manual along with a validated system to monitor intervention fidelity.
\end{abstract}

Keywords: Serious mental illness, adults, empowerment, dance, mindfulness, movement

About 11.2 million adults aged 18 or older in the United States are estimated to be living with serious mental illness (SMI; National Institute of Mental Health [NIMH], 2019). In contrast to those with mild or moderate mental illness, adults with SMI have mental, behavioral, or emotional disorders resulting in serious functional impairment, substantially interfering with one or more major life activities (NIMH, 2019). Major life activities may include caring for oneself, performing manual tasks, and concentrating, thinking, and communicating. Impairment in the capacity to engage in major life activities could negatively impact adults' performance of familial, spousal, and occupational roles.

Empowerment is critical to maximizing participation in major life activities. Empowerment has been shown to be an essential component to the self-management of mental health symptoms (Coulombe et al., 2015). Effective self-management of mental health symptoms could positively affect concentration, thinking, and communication as well as the enactment of social roles. Given that empowerment has been associated with the self-management of mental health symptoms, interventions to promote empowerment for adults with SMI are needed. Therefore, this study pilot-tested the efficacy of a movement and mindfulness workshop intervention, the Empowerment Through Movement and Stillness Workshop (ETMSW), to promote empowerment in adults with SMI.

Michael L. Clarkson-Hendrix, PhD, LCSW, Assistant Professor of Social Work in the Department of Sociocultural and Justice Sciences, and Paula J. Peters, MFA, is an Associate Professor of Dance in the Department of Theater and Dance at the State University of New York at Fredonia, NY. 


\section{Literature Review}

This literature review focused on three aspects important to the ETMSW intervention: (1) empowerment in adults with SMI, (2) empowerment and dance movement, and (3) empowerment and mindfulness.

\section{Empowerment in Adults With SMI}

Self-determination has been identified as an essential component of empowerment for SMI adults (Okon \& Webb, 2014; Sartorius, 2011). Although multiple empowerment definitions have been identified in the mental health literature (Barr et al., 2015; Castelein et al., 2008), the ETMSW intervention relied on Rogers, Chamberlin, Ellison, and Crean's (1997) definition of empowerment:

...a sense of self-worth, self-efficacy, and power. The empowered person recognizes use of anger as a motivating force to instigate social change and is optimistic about the ability to exert control over his or her life. He or she recognizes the importance of community to effect change, but the empowered person also values autonomy. (p. 1046)

In line with this definition of empowerment, Rogers and colleagues (1997) created an empirical model for empowering adults with SMI comprised of five aspects: self-esteemself-efficacy, power-powerlessness, community activism and autonomy, optimism and control over the future, and righteous anger (see Figure 1).

Empowerment has been shown to mediate recovery orientation and consumer satisfaction for adults with SMI (Barrett et al., 2010). Several factors have been found to be associated with empowerment, including demographic, life satisfaction, mental health, and social and occupational characteristics. Demographic characteristics that have been positively associated with empowerment include total monthly income (Rogers et al., 1997, 2010), marital status, age, and educational attainment (Rogers et al., 2010). Life quality and satisfaction characteristics have also been positively associated with empowerment (Rogers et al., 1997). Quality of life for adults with SMI (Bejerholm \& Björkman, 2011; Marchinko \& Clarke, 2011; Rogers et al., 1997, 2010), overall life satisfaction (Rogers et al., 1997, 2010), and self-rated health and client satisfaction (Hultqvist et al., 2015) have comprised these characteristics.

Mental health characteristics have also been associated with empowerment among SMI adults (Rogers et al., 1997). Empowerment has been positively associated with hope and sense of recovery (Rogers et al., 2010), Global Assessment of Functioning (Hultqvist et al., 2015), and an attitude of controllability over negative circumstances (Yamada \& Suzuki, 2007). In contrast, level of mental illness symptoms (Bejerholm \& Björkman, 2011; Rogers et al., 2010) and number of traditional mental health services received (Rogers et al., 1997) have been negatively associated with empowerment. The self-esteemself-efficacy aspect of empowerment has also been negatively associated with depressive symptoms (Bejerholm \& Björkman, 2011). 
Figure 1. Characteristics Associated With Empowerment for Adults With SMI

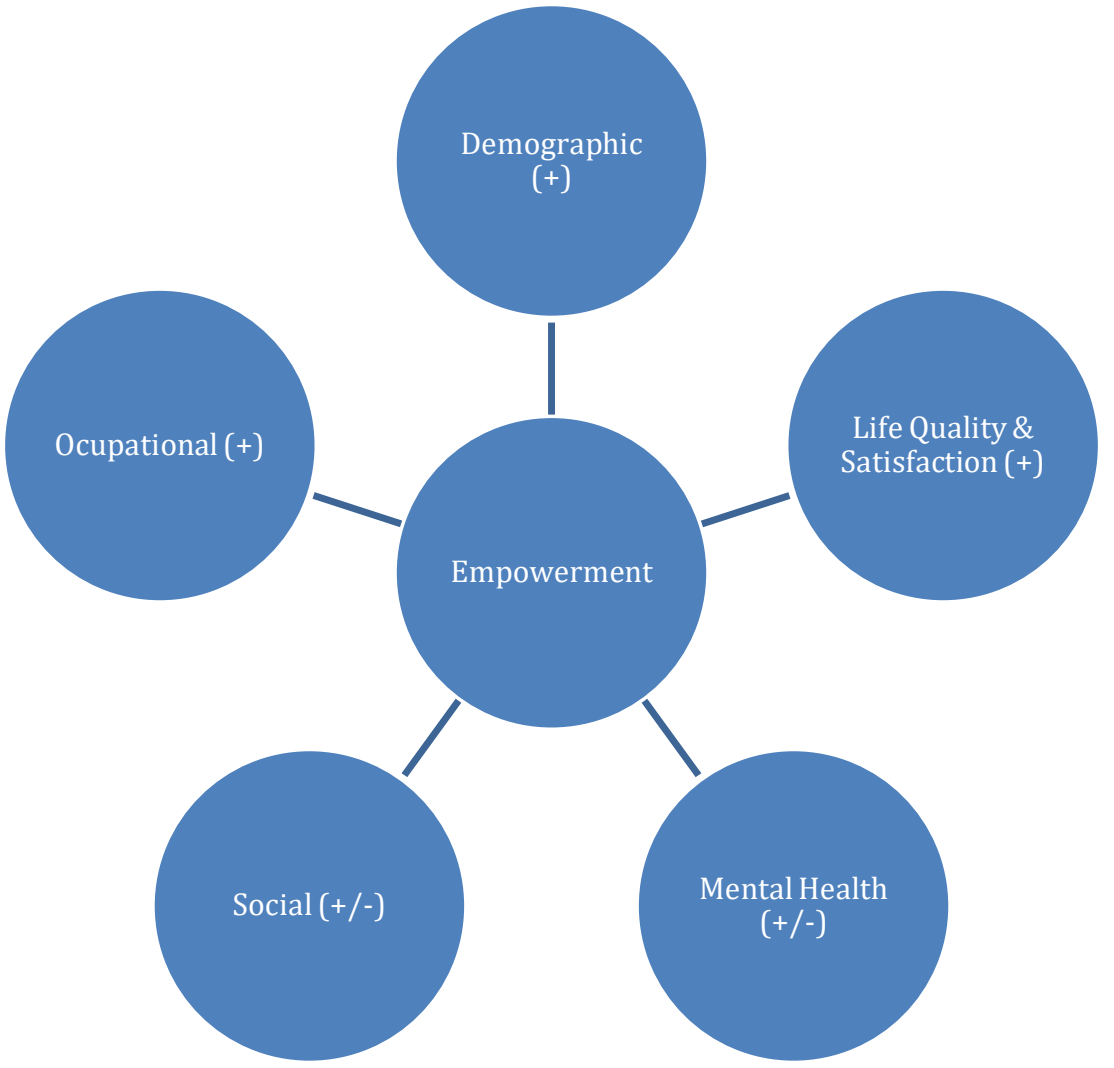

Note. $(+)=$ Positive associations with empowerment. $(+/-)=$ Both positive and negative associations with empowerment.

Empowerment has been positively and negatively associated with social characteristics for adults with SMI. Engagement in community activities (Bejerholm \& Björkman, 2011; Rogers et al., 1997), social acceptance, and objective and subjective social inclusion (Rogers et al., 2010) have been positively associated with empowerment. However, experienced stigma has been negatively associated with empowerment (Bejerholm \& Björkman, 2011).

Finally, empowerment (Rogers et al., 1997) has been positively associated with occupational characteristics for SMI adults. Employed status versus unemployed or retired status (Sá-Fernandes et al., 2018), occupational engagement (Hultqvist et al., 2015), and work rehabilitation (Bejerholm \& Björkman, 2011) have been positively associated with empowerment. Figure 1 summarizes characteristics associated with empowerment for SMI adults.

Interventions have been developed to improve empowerment (Rogers et al., 1997) for adults with SMI. Some of these interventions have focused on peer services (Hutchinson et al., 2006; Pickett et al., 2012; Russinova et al., 2018; Salzer et al., 2016) with mixed findings regarding improvements in empowerment. Participants in a peer-provider training 
program (Hutchinson et al., 2006), a peer-led education intervention (Pickett et al., 2012), and a peer-run photography-based group intervention (Russinova et al., 2018) reported gains in empowerment. However, a study of 99 participants with a schizophrenia spectrum or affective disorder that examined peer specialist services delivered through an independent living center did not find significant improvements in empowerment for those randomly assigned to receive peer services when compared to participants who received services as usual (Salzer et al., 2016).

A small group of studies that examined the impact of employment-oriented interventions found empowerment increased for the SMI adults involved in the interventions (Areberg \& Bejerholm, 2013; Hutchinson et al., 2006, 2007; Russinova et al., 2018). In contrast, significant improvements in empowerment were not found for 43 participants with psychosis who received a positive psychotherapy group intervention compared to 41 participants receiving services as usual (Schrank et al., 2016).

The impact of an intervention of a client-held medical record/crisis plan in booklet form was examined with 42 community mental health service participants. The researchers found that the dimensions of self-esteem-self-efficacy, community activism and autonomy, and optimism and control over the future increased between pre- and post-intervention (Marchinko \& Clarke, 2011). However, power-powerlessness and righteous anger did not evidence significant increases for the study participants. Additionally, research investigating a psychoeducational group empowerment program for adults with schizophrenia or a mood disorder found that the 25 participants receiving the group intervention, which was delivered by mental health professionals, significantly increased their empowerment when compared with the 38 control group participants (Hyun et al., 2019).

Although studies have identified peer- and employment-oriented as well as other interventions that have positively impacted empowerment, these interventions may not be applicable or amenable to all adults with SMI. More interventions with other approaches are needed to accommodate variation in learning styles. Arts-based approaches may be a promising source for additional interventions that support experiential learning styles. Arts-based approaches have been shown to encourage active engagement and decisionmaking (Morris \& Willis-Rauch, 2014), which is facilitative of empowerment. For example, although Russinova and colleagues' (2018) intervention was focused on employment, the approach used was photovoice, a photography-based group intervention, and the intervention resulted in increased empowerment for the 24 participants with psychiatric disabilities who received the intervention. The increase in empowerment was maintained at 3 months post-intervention. Additionally, Travis et al. (2019) successfully implemented a music and empowerment-based group with homeless SMI participants that resulted in positive social outcomes for the group participants.

\section{Empowerment and Dance Movement}

Dance, as a form of movement, has been identified as having both somatic and communicative features. This form of movement has been considered somatic in that the dancer consciously experiences their bodily self through movement (Eddy, 2009). The 
dancer becomes engaged in an embodied awareness that is grounded in the moment and the body (Purser, 2019). Dance has also been considered communicative in that the dancer uses movements to convey symbolic messages to the observer (Bannerman, 2014).

Studies of the use of dance as an empowerment intervention have focused on adolescents (Cappel, 1995; Duberg et al., 2016; Kotin et al., 2013) and adult women (Leseho \& Maxwell, 2010; Moe, 2014; Regehr, 2012). These interventions have linked increases in empowerment to improvements in mental health functioning for individuals with mild to moderate mental illness (Duberg et al., 2016; Leseho \& Maxwell, 2010; Regehr, 2012). Dance interventions have also resulted in decreased internalized sexism (Cappel, 1995; Moe, 2014; Regehr, 2012), classism (Cappel, 1995; Kotin et al., 2013), racism (Cappel, 1995; Kotin et al., 2013) and ageism (Moe, 2014). Roberts (2016) conceptualized that the embodied experience of movement in dance can empower individuals to exercise choice in how they express and present their identities.

\section{Empowerment and Mindfulness}

Mindfulness is "the awareness that emerges through paying attention on purpose, in the present moment, and nonjudgmentally to the unfolding of experience moment by moment" (Kabat-Zinn, 2003, p. 145). Various modalities have implemented mindfulness including psychotherapy (e.g., Harris, 2013), in-home individual skill-building programs (e.g., Brown \& Bellamy, 2017), and educational group sessions (e.g., Dhanalakshmi, 2019; Evans-Chase, 2015). Mindfulness has also been identified as a common practice element in evidence-based trauma treatment (Strand et al., 2013).

An essay describing a social work group intervention with six teen girls successfully implemented mindfulness techniques to not only improve emotional regulation and reduce maladaptive coping, but also to promote empowerment in group members (Sakhat, 2017). Additionally, training in mindful eating techniques has been applied to empower adults with SMI to engage in healthy eating habits with positive impacts related to over-eating and emotional eating (Gidugu \& Jacobs, 2019).

\section{Description of the ETMSW Intervention}

Based on the literature reviewed above, the authors developed the ETMSW intervention to promote somatic awareness of empowerment and integrate this awareness into participants' daily lives. Movement and mindfulness techniques were used to promote somatic awareness while group discussion techniques were used to integrate somatic awareness into the participants' daily lives.

Adults who received services from SMI-serving programs were the population of interest for the ETMSW intervention. SMI-serving programs focus on a subset of individuals with mental illness who experience significant functional limitations due to their illness. Day treatment, intensive outpatient mental health, community residential, and treatment apartment programs are some examples of SMI-serving programs. 
Since this project's purpose was to evaluate the preliminary intervention, the workshop was limited to three sessions. Each session focused on one aspect of Rogers, Chamberlin, Ellison, and Crean's (1997) empowerment model. The empowerment model aspects were self-esteem-self-efficacy, community activism and autonomy, and optimism and control over the future. The general structure of the 60-minute sessions involved the implementation of movement, mindfulness, and group discussion techniques. Sessions took place at participants' mental health programs and occurred once per week for 3 weeks.

\section{The Intervention Team}

The team was comprised of one dance specialist, one Licensed Clinical Social Worker (LCSW), and two dance students. The dance specialist, with a Master of Fine Arts in dance and approximately 30 years of experience in dance performance, choreography, and dance instruction, developed and implemented the movement techniques. The LCSW developed and implemented the mindfulness and discussion techniques. The two dance students provided additional visual examples of movement shapes as part of the movement sequences.

\section{Intervention Techniques}

Movement Techniques. Movement techniques implemented postmodern dance movement vocabulary by creating shapes aligned with cue words representing the session's key concept. Postmodern dance has employed "pedestrian" or everyday common shapes as its movement vocabulary to break down social binaries between dance movement and everyday movement (Dempster, 2008). Shapes were developed by adapting the idea of yogic postures through dance. Similar to dance, yogic postures have been understood as psychophysical practices that are directly related with the development of somatic awareness (de Campos et al., 2020; McCall et al., 2015). Dance techniques sought to use the body to create shapes that reflected the concepts within the empowerment model.

Cue words were vocalized by participants as they enacted the shapes in a sequence. Sequences were repeated several times to increase somatic awareness of the shapes. Shapes were implemented alongside a variety of music based on workshop participant interest and included rock, soul, and country music.

Mindfulness Techniques. Two mindfulness techniques were implemented during the workshop sessions. First, participants were guided to close or rest their eyes in a place of their choice while cue words were repeated, and they were asked to notice how their body felt when the words were spoken. Second, while still closing or resting their eyes, participants were asked to visualize themselves making the shapes while the cue words were repeated while again noticing how they felt in their body.

Discussion Techniques. Discussion techniques were used to process and reflect on the experience of movement and mindfulness. Each session, participants completed a one-page worksheet with questions asking about their perceptions of the movement and mindfulness experience, how they felt, and what they noticed about their body. Participants were then led through a facilitated discussion where they shared their responses and were asked to 
identify one thing they could do to bring the session's key concept more into their day-today lives.

\section{The Intervention Process}

Each session lasted approximately 60 minutes. Table 1 presents the empowerment aspects and cue words for each session.

Table 1. Session Numbers, Empowerment Aspects, and Cue Words

\begin{tabular}{c|l|l}
\hline Session & Empowerment aspect & Cue words \\
\hline 1 & Self-esteem-self-efficacy & $\begin{array}{l}\text { Accomplished, capable, certain, } \\
\text { confident, positive } \\
\text { Select, prefer, opt, pick }\end{array}$ \\
2 & Community activism and autonomy & \begin{tabular}{l} 
Limitless, optimistic, determined, action \\
\hline
\end{tabular} \\
\hline
\end{tabular}

The first 10 minutes of each workshop session focused on the completion of gentle stretching activities, which were led by the dance specialist with the support of the dance students. Then, the dance specialist along with the dance students progressed participants through the sequence of shapes for approximately 15 minutes. After implementing the sequence of shapes several times, the LCSW implemented mindfulness techniques for approximately 10 minutes. Following the mindfulness exercise, the LCSW led a discussion for approximately 15 minutes. The workshop session concluded with the dance specialist, with the support of the dance students, implementing the same sequence of shapes with participants for approximately 10 minutes. Figure 2 shows examples of the dance specialist enacting two shapes.

Figure 2. Example Shapes

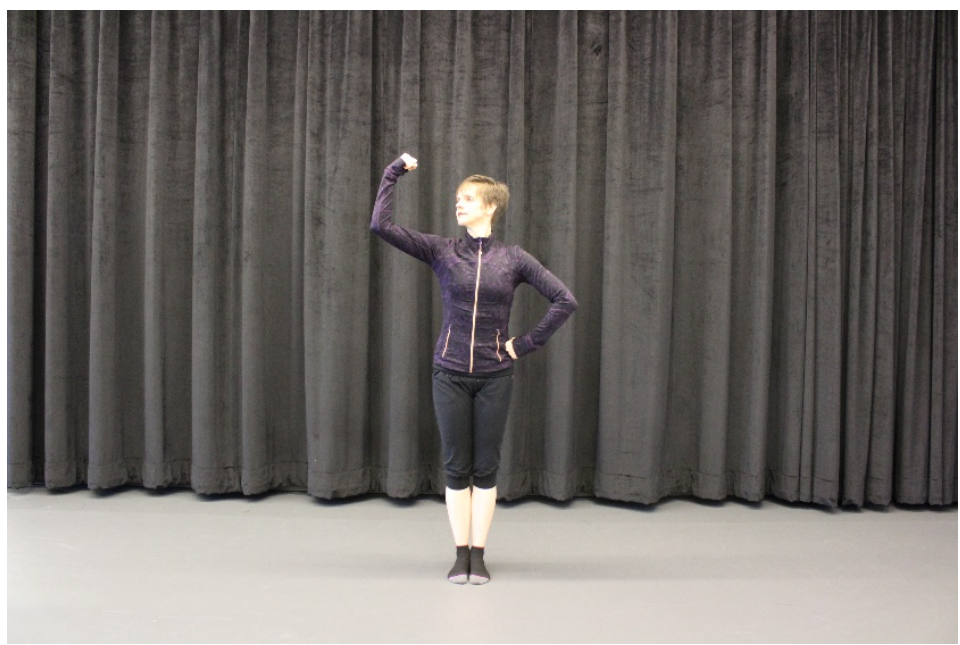




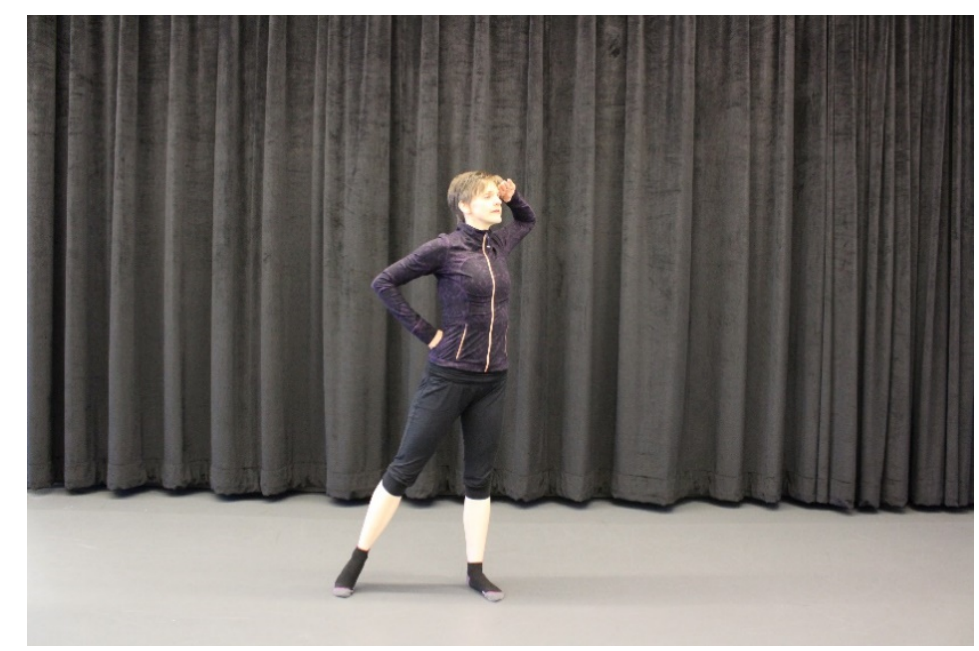

Note. Top panel: "Confident" shape from Session 1. Bottom panel:

"Limitless" shape from Session 3.

\section{Study Purpose}

This mixed methods pilot study evaluated the initial implementation of ETMSW. The movement and mindfulness techniques of ETMSW were designed to promote somatic awareness of empowerment while the discussion technique was developed to foster integration of this empowered awareness into participants' daily lives. If ETMSW resulted in increases in empowerment, the intervention may also enhance SMI participants' capacity to engage in major life activities crucial to the enactment of adult social roles. Quantitative data were used to examine differences in perceived empowerment before and after ETMSW, and qualitative data were used to explore SMI participants' perceptions of the reasons any differences in empowerment.

\section{Methods}

\section{Participants}

Participants in the empowerment workshop were adults currently receiving services in either a mental health day treatment program or mental health community residence in a northeastern state. Both programs exclusively served adults with SMI. Participants were enrolled in the study after meeting sampling criteria of being between the ages of 18 and 70 and could self-identify at least one mental health diagnosis.

Twelve adults initially volunteered to participate in the study. Two participants dropped out as the study progressed. One participant exited the study prior to the first workshop session. The other participant dropped out after the second session. The 10 participants who completed the intervention were mostly women $(n=7,70.0 \%)$ and White $(n=8,80.0 \%)$. On average, participants were in middle adulthood $(M=55.9$ years). Participants identified their most common mental health diagnoses as depression $(n=9$, 
$90.0 \%)$, anxiety $(n=5,50.0 \%)$, and bipolar disorder $(n=5,50.0 \%)$. Most participants completed 3 of 3 sessions $(n=7,70.0 \%)$ while the rest completed 2 of the 3 sessions $(n=3$, $30.0 \%)$.

Nine of the 10 study participants volunteered for and completed follow-up interviews. Most interview participants were women $(n=7,77.8 \%)$ and White $(n=7,77.8 \%)$. On average, interview participants were in middle adulthood ( $M=55.25$ years). Participants who completed interviews identified their most common mental health diagnoses as depression $(n=8,88.9 \%)$, anxiety $(n=4,44.4 \%)$, and bipolar disorder $(n=4,44.4 \%)$.

\section{Procedure}

After Institutional Review Board approval was received by the State University of New York at Fredonia, presentations were conducted at the residential group home and day treatment program to recruit participants for the project. After meeting screening criteria, prospective participants reviewed and signed informed consent forms. The consent forms reviewed the study purpose and procedures, and informed participants that they could discontinue their involvement in the project at any time without any penalties or loss of benefits associated with the residential or day treatment services they received.

Quantitative data were collected via pre- and post-intervention surveys. Preintervention surveys included items on participants' demographic characteristics, mental health diagnoses, and perceptions of empowerment. Post-intervention surveys asked about perceptions of empowerment.

Narrative data were collected through follow-up interviews with the participants. Interviews were completed approximately 2 to 3 weeks after the workshop sessions had concluded. An interview guide was used to structure the interviews (See Table 2). The interviews focused on changes in participants' conceptualizations of empowerment before and after the workshop and how they felt physically and emotionally after completing the workshop. Interviews were conducted face-to-face, tape-recorded, and transcribed verbatim.

\section{Table 2. Follow-up Interview Questions}

(1) Could you tell me a bit about what you thought empowerment was before you attended the workshop?

(2) As you were going through the workshop, what, if any, changes did you notice in how you felt about yourself?

(3) Did anything change about your sense of power or choice? If so, what changed?

(4) What about your sense of hope? What, if any changes did you notice as you did the workshop?

(5) How do you feel now that the workshop is over?

(6) Have there been any changes you have noticed after doing the workshop?

(7) How do you feel, in your body, now that you have done the workshop?

(8) In closing, is there anything else you would like to tell me about the workshop? 


\section{Instruments}

Empowerment. Three subscales from Rogers et al.'s (1997) Empowerment Scale were used to measure participants' self-perceptions of empowerment. These subscales were Self-Esteem-Self-Efficacy (9 items), Community Activism and Autonomy (8 items), and Optimism and Control Over the Future (4 items). Responses ranged from 1 (strongly disagree) to 5 (strongly agree). Concerning pre-intervention surveys, 3 items from the SelfEsteem-Self-Efficacy subscale, 5 items from the Community Activism and Autonomy subscale, and 2 items from the Optimism and Control Over the Future Subscale were removed to improve internal consistency reliability ( $\alpha=.90, \alpha=.96, \& \alpha=.75$, respectively). For post-intervention surveys, 3 items from the Self-Esteem-Self-Efficacy subscale, 2 items from the Community Activism and Autonomy subscale, and 2 items from the Optimism and Control Over the Future subscale were removed to improve internal consistency reliability ( $\alpha=.93, \alpha=.88, \& \alpha=.64$, respectively).

\section{Data Analysis}

Quantitative. Analysis involved examination of measures of central tendency and dispersion for the three empowerment subscales. Due to the small sample size, steps were taken to improve power to detect significant differences. These steps included improving the precision of the empowerment measures, as described above. Differences in empowerment subscales were examined using paired $t$-tests. Research has shown that $t$ tests are feasible for use with very small sample sizes (de Winter, 2013).

Qualitative. Thematic analysis was used to identify patterns of meaning from the perspective of the participants that could assist with understanding the quantitative results. Richards and Hemphill's (2018) guide to collaborative qualitative data analysis was followed with both the author and co-author analyzing the data cooperatively. Throughout the coding process, consensus coding was used. In consensus coding, analysts compare coded statements from the same transcripts and resolve coding discrepancies until an agreement is reached. Pseudonyms were used in describing the findings to ensure the confidentiality of the participants.

\section{Results}

\section{Quantitative}

Table 3 presents descriptive statistics for the empowerment subscales. Concerning the pre-intervention empowerment subscales, on average participants rated themselves as moderately high in perceived self-efficacy-self-esteem $(M=3.81$ on a 5 -point scale), community activism and autonomy ( $M=4.36$ on a 5 -point scale), and optimism and control over the future ( $M=3.67$ on a 5-point scale). For post-intervention empowerment subscales, they rated themselves as moderately high inself-efficacy-self-esteem $(M=4.41$ on a 5-point scale), high in community activism and autonomy ( $M=4.48$ on a 5 -point scale), and moderately high in optimism and control over the future ( $M=4.40$ on a 5 -point scale). 
Table 3. Descriptive Statistics for Empowerment Subscales

\begin{tabular}{l|cccc|cccc}
\hline \multirow{2}{*}{\multicolumn{1}{c|}{ Subscale }} & \multicolumn{4}{c|}{ Pre-intervention } & \multicolumn{4}{c}{ Post-intervention } \\
\cline { 2 - 9 } & $n$ & $M$ & $S D$ & Range & $n$ & $M$ & $S D$ & Range \\
\hline Self-esteem-self-efficacy & 12 & 3.81 & .62 & $2.44-4.89$ & 9 & 4.41 & .60 & $3.33-5.00$ \\
Community activism \& autonomy & 12 & 4.36 & .48 & $4.00-5.00$ & 10 & 4.48 & .55 & $3.83-5.00$ \\
Optimism \& control over the future & 12 & 3.67 & .98 & $1.50-4.50$ & 10 & 4.40 & .66 & $3.00-5.00$ \\
\hline
\end{tabular}

Bivariate results. Table 4 presents $t$-test results for empowerment subscales.

Perceptions of optimism and control over the future increased significantly between preand post-intervention surveys, $t(9)=1.89, p=.046, d=.598$. Perceptions of self-esteem-selfefficacy approached a statistically significant increase between pre- and post-intervention surveys $t(8)=1.79, p=.056, d=.597$. There were no statistically significant differences in perceived community activism and autonomy between pre- and post-intervention surveys, $t(8)=0.28, n s$.

Table 4. Results for t-tests Comparing Pre- and Post-Intervention Empowerment Subscales

\begin{tabular}{|c|c|c|c|c|c|c|c|c|}
\hline \multirow[b]{2}{*}{ Subscale } & \multicolumn{2}{|c|}{ Pre-intervention } & \multicolumn{2}{|c|}{ Post-intervention } & \multirow[b]{2}{*}{$t$} & \multirow[b]{2}{*}{$d f$} & \multirow[b]{2}{*}{$p$} & \multirow{2}{*}{$\begin{array}{l}\text { Cohen's } \\
d\end{array}$} \\
\hline & $M$ & $S D$ & $M$ & $S D$ & & & & \\
\hline Self-esteem-self-efficacy & 3.81 & .81 & 4.41 & .60 & 1.79 & 8 & .056 & .597 \\
\hline $\begin{array}{l}\text { Community activism \& } \\
\text { autonomy }\end{array}$ & 4.43 & .50 & 4.48 & .55 & .28 & 9 & .391 & .090 \\
\hline $\begin{array}{l}\text { Optimism \& control over } \\
\text { the future }\end{array}$ & 3.60 & 1.07 & 4.40 & .66 & 1.89 & 9 & .046 & .598 \\
\hline
\end{tabular}

\section{Qualitative}

Two themes were inducted from the interview data. These themes revealed that increases in optimism and control over the future may have been related to workshop accomplishments and reduced helplessness outside of workshop sessions.

Workshop accomplishments. Many adults who participated in the study discussed achievements within the workshop sessions that connected with a more positive outlook of themselves. When asked about what changed about her sense of hope as a result of the workshop, June stated, "I just felt more hopeful after the process, and it was very positive." When probed to elaborate on her response, she stated, "I liked the choices of the words. The word choices were good." She went on to state, "[The cue words] were making me look for the positive." She then went on to summarize how the workshop promoted her positive outlook: "I feel like I accomplished something, that was something in the [cue] words, so I felt like I accomplished something and benefited something. It was really good and helpful for me, too."

When asked about what, if any, changes April noticed about how she felt as she participated in the workshop, she stated, "[I] felt better. Oh ya, I was glad I was participating. I felt it was worth it... and I liked the moving attached to the thoughts." When probed about her response, April reported that saying the words while implementing the movement techniques was beneficial for her. She further elaborated: 
I felt more connected to life, to the moment, to that very day, and thinking about what I was gonna do that day, not overthinking about whatever problem or something bad, because I usually think about stuff that I would fail over, anyways, so it would be a waste of energy, but this made me focus and get more centered.

A final example of this theme comes from John who stated, "At first, the movements were awkward. I felt goofy doing it. After that, I felt easier doing it." With successive completions of the movements, he became more comfortable with them and successful in their execution. John stated, "You moved forward through it...I got used to it." With additional prompting, he elaborated, “.... it feels awkward, but you move, and you stay still, and think about it, and you move again. It is less awkward because you are used to it..."

Reduced helplessness. Some participants discussed feeling less helpless outside of the workshop sessions, which was connected with an increased capacity to act. June also discussed this theme in her interview. She stated, "[Before the workshop] I felt like I couldn't make a choice, and I felt that I would fail, and now I feel that I can make choices, the right choices, and I can feel empowerment." She elaborated, "I felt helpless before the empowerment [workshop], but now I feel like I am not as helpless, and hopeless." When asked about any changes that she had noticed after doing the workshop, June stated, "I look forward to the day now, and I look forward to Mondays now." When asked to elaborate further on any changes she noticed after doing the workshop, she stated, "I volunteered for the church. I sang for the church, so just getting out there."

April also presented an example of this theme. When asked about changes in her sense of power or choice as a result of the workshop, April shared how she was able to ask for help in emptying her storage unit. As the workshop progressed, she stated she felt "better" and "felt it's okay" to ask for help. In terms of her sense of hope, April stated:

I am really more hopeful now that I can take it, one step at a time and actually do it. I am part of it, and flow, not try to control things I cannot control, and let people help, [to] be more open with that, be more open personally. I can talk, and I can talk to you about my stuff, no problem. It [the workshop] was helping.

A final example of this theme comes from Susan. When asked about any changes she noticed in her sense of hope as she participated in the workshop, Susan stated she had a "stronger sense of hope." This idea of "stronger" was repeated when asked how she felt after completing the workshop. However, Susan also linked her sense of hope with increased assertiveness outside of workshop sessions. She stated, "I feel more stronger, a little more assertive." When asked what assertive meant to her, Susan stated, "It means getting your point across, kind of standing up for yourself without getting into swear words or fighting someone."

\section{Discussion}

The aim of this pilot study was to evaluate the initial implementation of ETMSW. Results of quantitative analyses show that optimism and control over the future, one aspect of empowerment (Rogers et al., 1997), increased between pre- and post-intervention 
surveys. The workshop participants perceived a greater sense of determination over what would happen in their life and an increase in optimism about the future.

Narrative data revealed that participants perceive the increase in optimism and control over the future may be related to accomplishments in the workshop and reduced helplessness outside of workshop sessions. Accomplishment has been identified as a central aspect of well-being (Gander et al., 2017) and has been associated with positive affect (Gabriel et al., 2011) and life satisfaction (Gander et al., 2017). Progressively achieving the movements may contribute to perceptions of optimism and determination.

The theme of reduced helplessness outside of workshop sessions is important since reduced feelings of helplessness have been associated with more mature coping styles, such as problem-solving rather than avoidance (Wang et al., 2017). The advancing physical repetition and mindful visualization of movements may show the participants that successive attempts can lead to positive outcomes, which may promote empowerment (Rogers et al., 1997). These within-session positive outcomes may engender optimism for acting outside of workshop sessions.

\section{Limitations}

Several limitations should be noted. Since this was a pilot study, more research is needed on the ETMSW intervention. Participants volunteered for the study. Results may not represent the broader population of adults with SMI. The study did not have a control group so the relative impacts of the intervention in comparison to other services participants received could not be disentangled. The design of the current study does not provide the capacity to understand where the change in optimism and control over the future stems from. The small number of participants limited the statistical power to detect significant differences in empowerment perceptions before and after the intervention and precluded multivariate analyses. Empowerment measures were self-report, which makes them vulnerable to social desirability and interpretive biases. Empowerment measures were not re-administered at a follow-up point post-intervention so maintenance of empowerment gains is unknown. Potential also exists for mono-method bias since a single measure of empowerment was administered. Consequently, sampling participants randomly, assigning them randomly to intervention and wait-list control groups, including a larger number of participants with one intervention group offered movement techniques only, a second mindfulness only, and a third both techniques, using multiple measures of empowerment, both self-report and objective measures, and re-administering empowerment measures at a follow-up point post-intervention are warranted.

In considering the qualitative aspect of this study, in general, these methods are vulnerable to researcher bias and a lack of generalizability (Creswell, 2014). Additionally, although consensus coding with two analysts was used to identify the themes, coding with other groups of analysts may have resulted in different themes. 


\section{Directions for Future Research}

This initial implementation study focused on three aspects of Rogers et al.'s (1997) empowerment model. In the future, we intend to develop and include sessions for the other two aspects of the model (i.e., power-powerlessness, righteous anger) as part of the intervention. Qualitative findings identified the themes of workshop accomplishments and reduced helplessness outside of workshop sessions. Future research would benefit from including measures representing these themes to assist with determining whether they impact empowerment differences. Creation of a training manual along with a validated system to monitor intervention fidelity is also needed.

\section{Implications for Social Work Practice}

Social workers should seek opportunities to partner with dance instructors to develop mindful-movement interventions. Dance's somatic features can provide expansive resources to support mindfulness embodiment. Mindful-movement interventions may be particularly beneficial for clients who have experiential learning styles.

\section{Conclusion}

Adults with SMI live with severe functional impairments, and empowerment can be critical to maximizing their participation in major life activities. Currently established interventions to promote empowerment may be useful for some SMI adults, and not as beneficial with others. Therefore, additional movement and mindfulness interventions need examination. We recommend social workers consider using mindful-movement interventions to maximize participation in major life activities for adults with SMI.

\section{References}

Areberg, C., \& Bejerholm, U. (2013). The effect of IPS on participants' engagement, quality of life, empowerment, and motivation: A randomized controlled trial. Scandinavian Journal of Occupational Therapy, 20(6), 420-428. https://doi.org/10.3109/11038128.2013.765911

Bannerman, H. (2014). Is dance a language? Movement, meaning and communication. Dance Research, 32(1), 65-80. https://doi.org/10.3366/drs.2014.0087

Barr, P. J., Scholl, I., Bravo, P., Faber, M. J., Elwyn, G., \& McAllister, M. (2015). Assessment of patient empowerment: A systematic review of measures. PLOS ONE, 10(5), 1-25. https://doi.org/10.1371/journal.pone.0126553

Barrett, B., Young, M. S., Teague, G. B., Winarski, J. T., Moore, K. A., \& Ochshorn, E. (2010). Recovery orientation of treatment, consumer empowerment, and satisfaction with services: A mediational model. Psychiatric Rehabilitation Journal, 34(2), 153156. https://doi.org/10.2975/34.2.2010.153.156

Bejerholm, U., \& Björkman, T. (2011). Empowerment in supported employment research and practice: Is it relevant? International Journal of Social Psychiatry, 57(6), 588- 
595. https://doi.org/10.1177/0020764010376606

Brown, S. M., \& Bellamy, J. (2017). Feasibility, acceptability, and clinical trends of a mindfulness-informed child welfare intervention: Implications for trauma-focused practice. Advances in Social Work, 18(1), 369-386. https://doi.org/10.18060/21281

Cappel, M. L. (1995). Sista-2-Sista: A self-empowerment program. Journal of Physical Education, Recreation \& Dance, 66(4), 43-45. https://doi.org/10.1080/07303084.1995.10608138

Castelein, S., van der Gaag, M., Bruggeman, R., van Busschbach, J. T., \& Wiersma, D. (2008). Measuring empowerment among people with psychotic disorders: A comparison of three instruments. Psychiatric Services, 59(11), 1338-1342. https://doi.org/10.1176/appi.ps.59.11.1338

Coulombe, S., Radziszewski, S., Trépanier, S.-G., Provencher, H., Roberge, P., Hudon, C., Meunier, S., Provencher, M. D., \& Houle, J. (2015). Mental health selfmanagement questionnaire: Development and psychometric properties. Journal of Affective Disorders, 181, 41-49. https://doi.org/10.1016/j.jad.2015.04.007

Creswell, J. (2014). Research design: Qualitative, quantitative, and mixed methods approaches (4th ed.). Sage.

de Campos, E. A., Narchi, N. Z., \& Moreno, G. (2020). Meanings and perceptions of women regarding the practice of yoga in pregnancy: A qualitative study. Complementary Therapies in Clinical Practice, 39, 1-6. https://doi.org/10.1016/j.ctcp.2020.101099

de Winter, J. C. F. (2013). Using the student's t-test with extremely small sample sizes. Practical Assessment, Research and Evaluation, 18(10), 1-12. https://doi.org/10.7275/e4r6-dj05

Dempster, E. (2008). The choreography of the pedestrian. Performance Research, 13(1), 23-28. https://doi.org/10.1080/13528160802465458

Dhanalakshmi, D. (2019). Mindfulness-Based Stress Reduction (MBSR) to reduce anxiety, improve sense of coherence, optimism and general health among students. IAHRW International Journal of Social Sciences, 7(1), 121-127.

Duberg, A., Möller, M., \& Sunvisson, H. (2016). "I feel free": Experiences of a dance intervention for adolescent girls with internalizing problems. International Journal of Qualitative Studies on Health and Well-Being, 11(1). https://doi.org/10.3402/qhw.v11.31946

Eddy, M. (2009). A brief history of somatic practices and dance: Historical development of the field of somatic education and its relationship to dance. Journal of Dance and Somatic Practices, 1(1), 5-27. https://doi.org/10.1386/jdsp.1.1.5/1

Evans-Chase, M. (2015). If they like it they can take it with them: A mixed methods look at the use of internet-based instruction of mindfulness meditation with incarcerated youth. Advances in Social Work, 16(1), 90-106. https://doi.org/10.18060/17973 
Gabriel, A. S., Diefendorff, J. M., \& Erickson, R. J. (2011). The relations of daily task accomplishment satisfaction with changes in affect: A multilevel study in nurses. Journal of Applied Psychology, 96(5), 1095-1104. https://doi.org/10.1037/a0023937

Gander, F., Proyer, R. T., \& Ruch, W. (2017). The subjective assessment of accomplishment and positive relationships: Initial validation and correlative and experimental evidence for their association with well-being. Journal of Happiness Studies, 18, 743-764. https://doi.org/10.1007/s10902-016-9751-z

Gidugu, V., \& Jacobs, M. L. (2019). Empowering individuals with mental illness to develop healthy eating habits through mindful eating: Results of a program evaluation. Psychology, Health and Medicine, 24(2), 177-186. https://doi.org/10.1080/13548506.2018.1516295

Harris, W. (2013). Mindfulness-Based Existential Therapy: Connecting mindfulness and existential therapy. Journal of Creativity in Mental Health, 8(4), 349-362. https://doi.org/10.1080/15401383.2013.844655

Hultqvist, J., Eklund, M., \& Leufstadius, C. (2015). Empowerment and occupational engagement among people with psychiatric disabilities. Scandinavian Journal of Occupational Therapy, 22(1), 54-61. https://doi.org/10.3109/11038128.2014.934916

Hutchinson, D., Anthony, W. A., Ashcraft, L., Johnson, E., Dunn, E. C., Lyass, A., \& Rogers, E. S. (2006). The personal and vocational impact of training and employing people with psychiatric disabilities as providers. Psychiatric Rehabilitation Journal, 29(3), 205-213. https://doi.org/10.2975/29.2006.205.213

Hutchinson, D., Anthony, W., Massaro, J., \& Rogers, E. S. (2007). Evaluation of a combined supported computer education and employment training program for persons with psychiatric disabilities. Psychiatric Rehabilitation Journal, 30(3), 189197. https://doi.org/10.2975/30.3.2007.189.197

Hyun, M. S., Kim, H., \& Nam, K. A. (2019). Effects of an empowerment program for community-dwelling people with mental illness in South Korea. Perspectives in Psychiatric Care, 55(1), 15-22. https://doi.org/10.1111/ppc.12273

Kabat-Zinn, J. (2003). Mindfulness-based interventions in context: Past, present, and future. Clinical Psychology: Science and Practice, 10(2), 144-156. https://doi.org/10.1093/clipsy/bpg016

Kotin, A., Mcgregor, S. A., Pellecchia, D., Schatz, I., \& Liu, S. P. (2013). Speak out. Act up. Move forward. Disobedience-based arts education. Harvard Educational Review, 83(1), 190-200. https://doi.org/10.17763/haer.83.1.x2j8070452124kv3

Leseho, J., \& Maxwell, L. R. (2010). Coming alive: Creative movement as a personal coping strategy on the path to healing and growth. British Journal of Guidance \& Counselling, 38(1), 17-30. https://doi.org/10.1080/03069880903411301

Marchinko, S., \& Clarke, D. (2011). The Wellness Planner: Empowerment, quality of life, and continuity of care in mental illness. Archives of Psychiatric Nursing, 25(4), 284-293. https://doi.org/10.1016/j.apnu.2010.10.003 
McCall, M., Thorne, S., Ward, A., \& Heneghan, C. (2015). Yoga in adult cancer: An exploratory, qualitative analysis of the patient experience. BMC Complementary and Alternative Medicine, 15(1), 1-10. https://doi.org/10.1186/s12906-015-0738-9

Moe, A. M. (2014). Sequins, sass, and sisterhood: An exploration of older women's belly dancing. Journal of Women and Aging, 26(1), 39-65. https://doi.org/10.1080/08952841.2014.854574

Morris, F. J., \& Willis-Rauch, M. (2014). Join the art club: Exploring social empowerment in art therapy. Art Therapy, 31(1), 28-36. https://doi.org/10.1080/07421656.2014.873694

National Institute of Mental Health. (2019). Mental Illness. https://www.nimh.nih.gov/health/statistics/mental-illness.shtml

Okon, S., \& Webb, D. (2014). Self-determination: A curriculum of empowerment for health and wellness in a psychosocial rehabilitation clubhouse. Occupational Therapy in Mental Health, 30(2), 196-212. https://doi.org/10.1080/0164212X.2014.911672

Pickett, S. A., Diehl, S. M., Steigman, P. J., Prater, J. D., Fox, A., Shipley, P., Grey, D. D., \& Cook, J. A. (2012). Consumer empowerment and self-advocacy outcomes in a randomized study of peer-led education. Community Mental Health Journal, 48(4), 420-430. https://doi.org/10.1007/s10597-012-9507-0

Purser, A. (2019). Dancing intercorporeality: A health humanities perspective on dance as a healing art. Journal of Medical Humanities, 40(2), 253-263. https://doi.org/10.1007/s10912-017-9502-0

Regehr, K. (2012). The rise of recreational burlesque: Bumping and grinding towards empowerment. Sexuality and Culture, 16(2), 134-157. https://doi.org/10.1007/s12119-011-9113-2

Richards, K. A. R., \& Hemphill, M. A. (2018). A practical guide to collaborative qualitative data analysis. Journal of Teaching in Physical Education, 37, 225-231. https://doi.org/10.1123/jtpe.2017-0084

Roberts, N. G. (2016). Embodying self: A dance/movement therapy approach to working with concealable stigmas. American Journal of Dance Therapy, 38(1), 63-80. https://doi.org/10.1007/s10465-016-9212-6

Rogers, E. S., Chamberlin, J., Ellison, M. L., \& Crean, T. (1997). A consumerconstructed scale to measure empowerment among users of mental health services. Psychiatric Services, 48(8), 1042-1047. https://doi.org/10.1176/ps.48.8.1042

Rogers, E. S., Ralph, R. O., \& Salzer, M. S. (2010). Validating the empowerment scale with a multisite sample of consumers of mental health services. Psychiatric Services, 61(9), 933-936. https://doi.org/10.1176/appi.ps.61.9.933

Russinova, Z., Gidugu, V., Bloch, P., Restrepo-Toro, M., \& Sally Rogers, E. (2018). Empowering individuals with psychiatric disabilities to work: Results of a 
randomized trial. Psychiatric Rehabilitation Journal, 41(3), 196-207. https://doi.org/10.1037/prj0000303

Sá-Fernandes, L., Jorge-Monteiro, M. F., \& Ornelas, J. (2018). Empowerment promotion through competitive employment for people with psychiatric disabilities. Journal of Vocational Rehabilitation, 49(2), 259-263. https://doi.org/10.3233/JVR-180971

Sakhat, Z. (2017). Butterflies. Social Work with Groups, 40(4), 308-314. https://doi.org/10.1080/01609513.2016.1217481

Salzer, M. S., Rogers, J., Salandra, N., O’Callaghan, C., Fulton, F., Balletta, A. A., Pizziketti, K., \& Brusilovskiy, E. (2016). Effectiveness of peer-delivered Center for Independent Living supports for individuals with psychiatric disabilities: A randomized, controlled trial. Psychiatric Rehabilitation Journal, 39(3), 239-247. https://doi.org/10.1037/prj0000220

Sartorius, N. H. (2011). Empowerment and mental health. European Psychiatry, 26(S2), 2100-2100. https://doi.org/10.1016/s0924-9338(11)73803-2

Schrank, B., Brownell, T., Jakaite, Z., Larkin, C., Pesola, F., Riches, S., Tylee, A., \& Slade, M. (2016). Evaluation of a positive psychotherapy group intervention for people with psychosis: Pilot randomised controlled trial. Epidemiology and Psychiatric Sciences, 25(3), 235-246. https://doi.org/10.1017/S2045796015000141

Strand, V. C., Hansen, S., \& Courtney, D. (2013). Common elements across evidencebased trauma treatment: Discovery and implications. Advances in Social Work, 14(2), 334-354. https://doi.org/10.18060/3052

Travis, R., Rodwin, A. H., \& Allcorn, A. (2019). Hip Hop, empowerment, and clinical practice for homeless adults with severe mental illness. Social Work with Groups, 42(2), 83-100. https://doi.org/10.1080/01609513.2018.1486776

Wang, C. Y., Zhang, K., \& Zhang, M. (2017). Dysfunctional attitudes, learned helplessness, and coping styles among men with substance use disorders. Social Behavior and Personality, 45(2), 269-280. https://doi.org/10.2224/sbp.5825

Yamada, S., \& Suzuki, K. (2007). Application of Empowerment Scale to patients with schizophrenia: Japanese experience. Psychiatry and Clinical Neurosciences, 61(6), 594-601. https://doi.org/10.1111/j.1440-1819.2007.01723.x

Author note: Address correspondence to Michael Clarkson-Hendrix, Department of Sociocultural and Justice Sciences, State University of New York at Fredonia, Fredonia, NY 14063. Email: michael.clarkson-hendrix@,fredonia.edu 